\title{
DETERMINING THE PROBABILITY OF LIGHTNING STRIKING THE DEVICE ASSEMBLY FACILITY
}

MECENED

R. T. Hasbrouck

Defense Sciences Engineering Division Field Systems Instrumentation Group

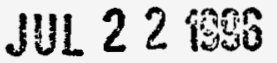

OSTI

June 7, 1996

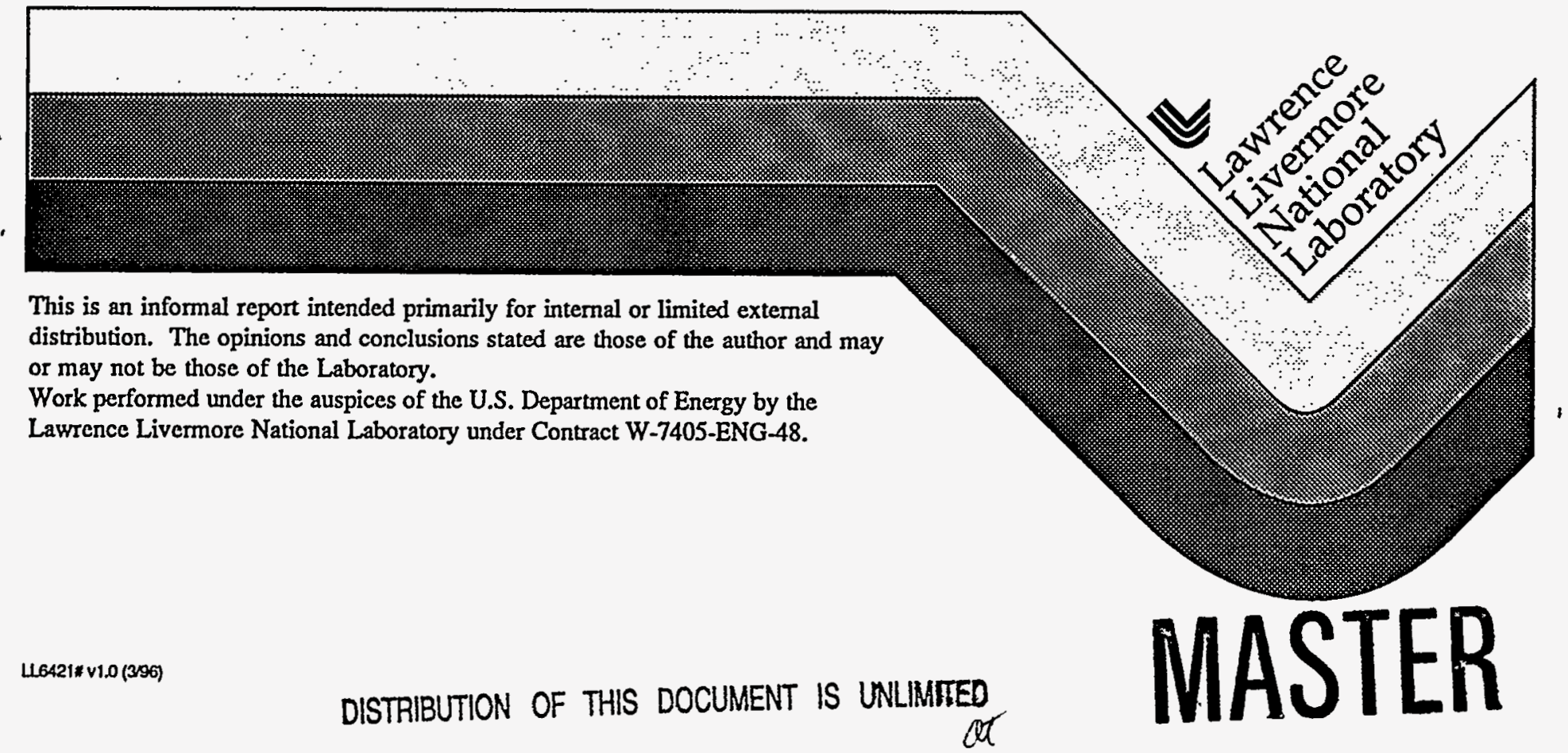




\section{DISCLAIMER}

This document was prepared as an account of work sponsored by an agency of the United. States Government. Neither the United States Government nor the University of California nor any of their employees, makes any warranty, express or implied, or assumes any legal liability or responsibility for the accuracy, completeness, or usefulness of any information, apparatus, product, or process disclosed, or represents that its use would not infringe privately owned rights. Reference herein to any specific commercial product, process, or service by trade name, trademark, manufacturer, or otherwise, does not necessarily constitute or imply its endorsement, recommendation, or favoring by the United States Government or the University of California. The views and opinions of authors expressed herein do not necessarily state or reflect those of the United States Government or the University of California, and shall not be used for advertising or product endorsement purposes.

This report has been reproduced directly from the best available copy.

Available to DOE and DOE contractors from the Office of Scientific and Technical Information P.O. Box 62, Oak Ridge, TN 37831

Prices available from (615) 576-8401, FTS 626-8401

Available to the public from the

National Technical Information Service

U.S. Department of Commerce

5285 Port Royal Rd.

Springfield, VA 22161 


\section{DISCLAIMER}

Portions of this document may be illegible in electronic image products. Images are produced from the best available original document. 
UCRL-ID-123334

\title{
DETERMINING THE PROBABILITY OF LIGHTNING STRIKING THE DEVICE ASSEMBLY FACILITY
}

\author{
R.T. Hasbrouck \\ Defense Sciences Engineering Division \\ Field Systems Instrumentation Group
}

$6 / 07 / 96$

Lawrence Livermore National Laboratory

Livermore, California 94550 


\author{
R.T. Hasbrouck \\ Lawrence Livermore National Laboratory
}

\begin{abstract}
The likelihood of lightning striking a new facility at the Nevada Test Site (NTS) has been considered in conjunction with a Lightning Hazard Mitigation study for that facility. Probability was estimated using both an older "traditional" method and a new method in which five years of actual NTS lightning strike data was analyzed. We believe the new method provides a more credible estimate. An important finding is that the NTS data exhibits a distribution of return-stroke peak-current amplitudes that is significantly less severe than that generally used by the lightning protection community, or found in other parts of the United States.
\end{abstract}

\title{
BACKGROUND
}

The Device Assembly Facility (DAF) is located at the Nevada Test Site. It consists of a very large, partially earth-covered, reinforced-concrete structure (referred to hereafter as the DAF structure, or the structure). It is encompassed by 12 tall, grounded, metal light poles. Although the facility also contains several much smaller outbuildings, they are not considered in this analysis. One task of the DAF Lightning Hazard Mitigation study was to determine the likelihood of the DAF or its perimeter light poles being struck by lightning. This paper presents two different approaches used to estimate that likelihood

\section{ESTIMATING PROBABILITY-GENERAL}

In the first method, the probability of lightning striking a particular object situated on the earth (ground) is found by multiplying the object's lightning-attractive area by the local ground-flash density (lightning strikes to ground per $\mathrm{km}^{2}$ per year). The second method uses a computer program, $F L A S H$, to subject a $1-\mathrm{km}^{2}$ area to a large number of randomly generated, simulated lightning strikes. Coordinates representing the object's ground surface area and height are used to center it within the 1$\mathrm{km}^{2}$ strike area.

\section{CAVEATS}

It must be understood that calculations used for determining strike probability are based upon empirical relationships, generally accepted by the research community as reasonably representing the lightning phenomenon. The methods presented here provide reasonable estimates but should not be considered the "final word." Other, more complicated geometric methods could be used, but considering the variability of lightning data they can't be expected to significantly improve accuracy.

A complete lightning event, referred to as a flash, consists of one or more return strokes. Return strokes are high-peak-amplitude (10s-100s of thousands of amperes) current pulses lasting for a few hundred microseconds. The average number of strokes per negative flash (multiplicity) is between three and four. Approximately $25 \%$ of all negative flashes (the most common type) also exhibit several hundred amperes of continuing current, lasting for 100 s of milliseconds following at least one stroke. In a given flash, consecutive return strokes may strike the ground within several meters of each other, or as far apart as $3 \mathrm{~km}$. Analyses indicate that they exhibit a "random walk" having a mean interstroke distance of $1.8 \mathrm{~km}$. The actual flash density data used in this report is based upon the location of each flash's first detected stroke, regardless of its amplitude. It is believed that no strike probability estimates have been made that take into account the area encompassed by a flash, its multiplicity and the current-amplitude distribution of strokes per-flash. (Note that the significantly less frequent 
positive lightning flash usually consists of a single stroke-having statistically higher average and maximum amplitudes-accompanied by continuing current, and lasts for as long as two seconds.)

\section{METHOD 1-CUMULATIVE PROBABILTTY}

The following explains the several terms used in estimating probability.

\section{Lightning Attractive Area}

If the surface beneath a storm cloud were perfectly flat, lightning would strike any point on the surface with equal probability. For example, if the ground-flash density was one flash per $\mathrm{km}^{2}$ per year and the area of concern was flat, with an area $0.1 \mathrm{~km}^{2}$, the probability of its being struck would be 0.1 flashes per year (a return frequency of 10 years per flash). However, a conductive object that is taller than the surrounding area exhibits a lightning attractive area greater than the ground surface area it occupies. The probability of its being struck is a function of its ground surface area, height, and the striking distance between the tip of the downward-moving lightning stepped leader and the object (Ref. 1). For negative lightning the stepped leader is a negatively charged channel that travels, in discrete jumps, from cloud to Earth.

Striking distance is the stepped leader's final jump to the conductive object and varies with the amount of charge carried by the channel. (Note: For the sake of simplicity, striking distance calculations don't take into account upward-moving, positively-charged streamers emanating from conductive objects under the influence of the stepped leader's strong electric field-much like hairs rising up toward a statically charged comb held over the head.) Since the magnitude of this charge also determines return-stroke peak-current amplitude, greater striking distance is associated with a larger amplitude return stroke, i.e., it jumps farther to reach the object (Ref. 2). Thus, for a given ground surface area and object height, the greatest attractive area is associated with the lightning stroke having the largest peak amplitude.

\section{Ground-Flash Density}

Ground-flash density can be calculated using two different empirically derived equations (Refs. 3 \& 4)-one based upon annual thunderstorm days and the other on annual average thunderstorm duration in hours (see Table 1). (Note: Values for thunderstorm days and hours are taken from contour plots that cover large geographic areas. Data for these plots have been gathered over a period of two to three decades by observers trained by the weather service. Any day on which thunder is heard-whether it is one or several hundred "booms" -is recorded as one thunderstorm day.) Using both methods, and a thunderstorm day value of $20 / \mathrm{yr}$, ground-flash density values of $2-5.5$ flashes $/ \mathrm{km}^{2} / \mathrm{yr}$ were calculated for the NTS (latitude N $36.9^{\circ}$ ).

New technology has brought about a dramatic improvement in the determination of ground-flash density. Actual cloud-to-ground lightning strike data-detected and archived by the National Lightning Detection Network (NLDN)-are analyzed by Global Atmospherics, Inc. (GAI). The product is a ground-flash density map for a specific area. The DAF probability study used a map (Fig. 1) depicting five years of NTS data. A total of 29,207 negative and positive flashes were recorded within an area, centered on the DAF site, of $1.3 \times 10^{4} \mathrm{~km}^{2}\left(0.45\right.$ flashes $\left./ \mathrm{km}^{2} / \mathrm{yr}\right)$. Ground-flash density within a $4-\mathrm{km}$ radius, centered on the DAF, ranged from $<0.25$ to $<0.5$ flashes $/ \mathrm{km}^{2} / \mathrm{yr}$-one-tenth the values determined by the aforementioned method.

The following should be taken into account when considering the GAI data. NLDN detection efficiency (DE)-i.e., the percentage of all lightning flashes that were detected and recorded-has improved over the five-year period during which our data was acquired. Initially, DE was reported as 65-70\%, increasing to its current range of $85-90 \%$. Using a five-year DE average of $75 \%$ (considered by GAI to be a reasonable estimate) gives a corrected DAF flash-density range of $<0.33$ to $<0.67$. The median value of 0.5 flashes $/ \mathrm{km}^{2} / \mathrm{yr}$ was used for our probability calculations. 
Table 1. Calculation of Ground-Flash Density

\begin{tabular}{|c|c|}
\hline Equation 1 (based on thunderstorm days) & Equation 2 (based on thunderstorm hours) \\
\hline $\begin{aligned} \mathbf{R} & =\text { Ratio of C-G to total lightning * } \\
& =0.1 \times\left(1+(\text { Lat. } / 30)^{2}\right) \\
\text { Lat. } & =\quad \text { Latitude of site [in degrees] }\end{aligned}$ & $\begin{aligned} \mathbf{f}_{\mathrm{t}} & =\text { Total daily flash density } \\
& =(\mathrm{fl} / \mathrm{min} .) \times\left(\min . / \text { storm } / \mathrm{T}_{\mathrm{d}}\right) \times\left(\text { storm } / \mathrm{km}^{2}\right) \\
& =0.4 \text { to } 1.1 \quad\left[\mathrm{fl} / \mathrm{km}^{2} / \mathrm{T}_{\mathrm{d}}\right]\end{aligned}$ \\
\hline$T_{d}=\begin{array}{l}\text { Thunderstorm days } / y r \\
\text { [from isokeraunic map] }\end{array}$ & [Based upon $3 \mathrm{fl} / \mathrm{min} ., 1-3 \mathrm{~h} / \mathrm{storm} / \mathrm{T}_{\mathrm{d}}$, and $500 \mathrm{~km}^{2} / \mathrm{storm}$.] \\
\hline $\begin{aligned} \mathrm{F}_{\mathrm{g}} & =\text { Ground-flash density, }\left[\mathrm{f} / \mathrm{km}^{2} / \mathrm{yr}\right] \\
& =\mathrm{R} \times\left(0.02 \times \mathrm{T}_{\mathrm{d}}{ }^{1.7}\right)\end{aligned}$ & $\begin{array}{lll}F_{g}= & f_{t} \times T_{d} \times R \\
F_{g \text { min }}=0.4 \times T_{d} \times R \quad \text { [1-hour storm } \\
\text { duration] } \\
F_{g_{\max }}=1.1 \times T_{d} \times R \quad \text { [3-hour storm duration] }\end{array}$ \\
\hline
\end{tabular}

* Total lightning includes intracloud, cloud-to-ground and intercloud. Although total lightning is less for the more northern latitudes, their colder ambient temperatures result in lower cloud-base altitudes, allowing a greater percentage of the lightring to be cloud-to-ground.

Fig. 1. NTS Ground-flash density map for five-year period, centered on Device Assembly Facility.

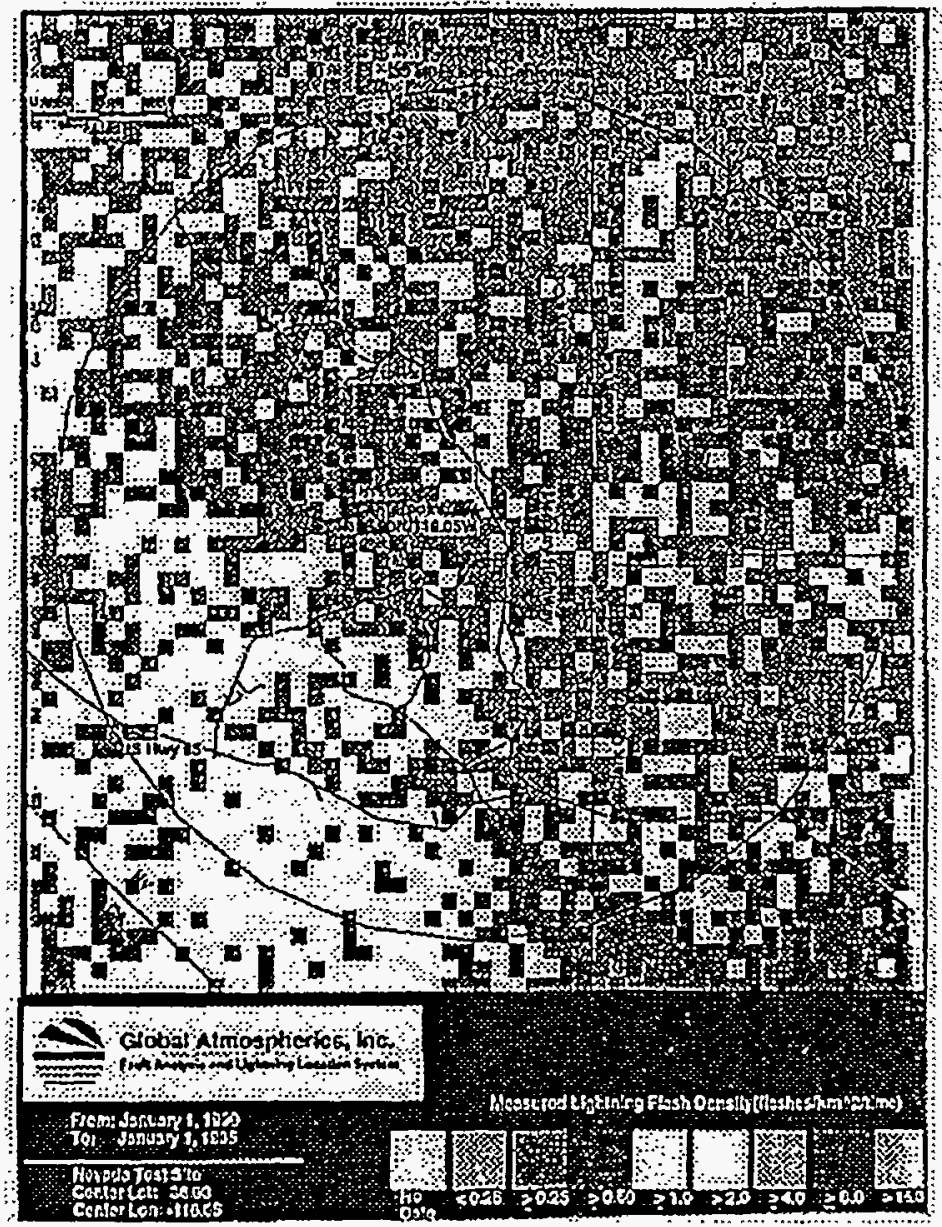


Over a number of decades, researchers have measured and recorded a variety of lightning parameters, with much of the data having been taken from instrumented steel towers. Along with current rate of rise and total charge transfer, peak return-stroke current is considered to be one of lightning's most significant threat parameters. Figure 2 depicts the generally accepted frequency distribution of peak currents (for negative lightning). The 1st-percentile value, $200 \mathrm{kA}$ (i.e., $99 \%$ of all lightning is of lower amplitude), is typically considered to be a severe stroke.

In addition to the previously discussed ground-flash density map, GAI provided histograms of estimated peak currents associated with the 29,207 flashes. The data were grouped into 5-kA-wide bins and plotted versus the number of flashes per bin (Figs. 3a and $3 \mathrm{~b}$ ). GAI pointed out that the NTS peakcurrent distribution is lower than elsewhere in the US. The GAI data were used to prepare a plot (Fig. 4) that shows the percent of strokes having peak currents less than the peak current indicated on the $x$ axis. This curve is significant in that the 50th-percentile value is $15 \mathrm{kA}$ and the 1 st-percentile is $60 \mathrm{kA}$, compared to $20 \mathrm{kA}$ and (approximately) $200 \mathrm{kA}$, respectively, as shown in Fig. 2. Based upon this data, we observe that the vast majority of the lightning at DAF can be expected to be of low-to-moderate amplitudes, with $99.99 \%$ being less than the severe $200-\mathrm{kA}$ level.

Although the NLDN detection efficiency is less than $100 \%$, it is low current events that are missed. Thus, had all flashes been detected, the distribution of peak-current amplitudes would show a somewhat lower average value.

Fig. 2. Distribution of peak currents for first return stroke (from Cianos and Pierce, A Ground Lightning Environment for Engineering Usage, Stanford Research Institute Technical Report LS-2817-A3, Menlo Park, CA, 1972).

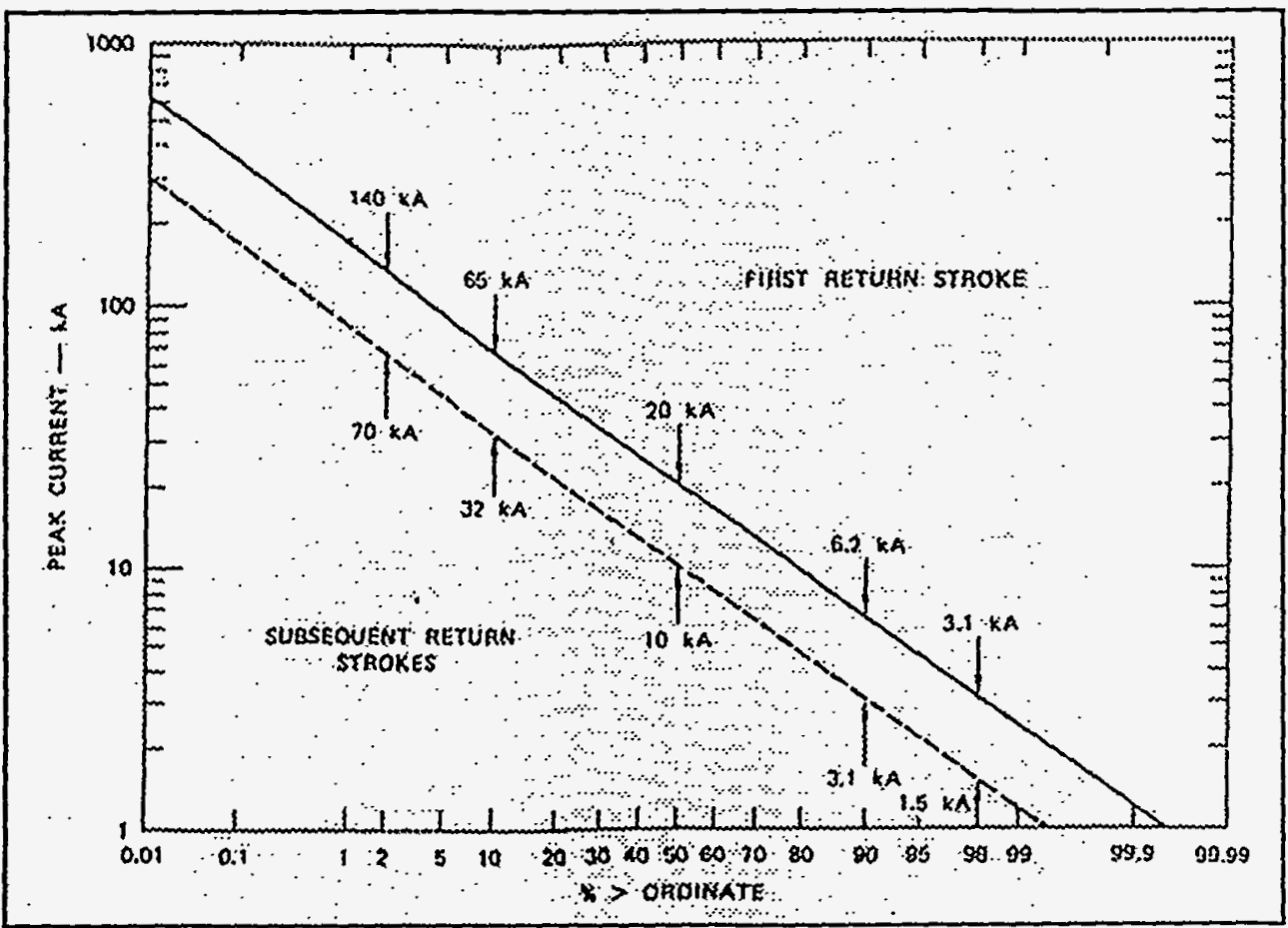


Fig. 3a. Histogram of NTS estimated flash peak current frequency (positive polarity).

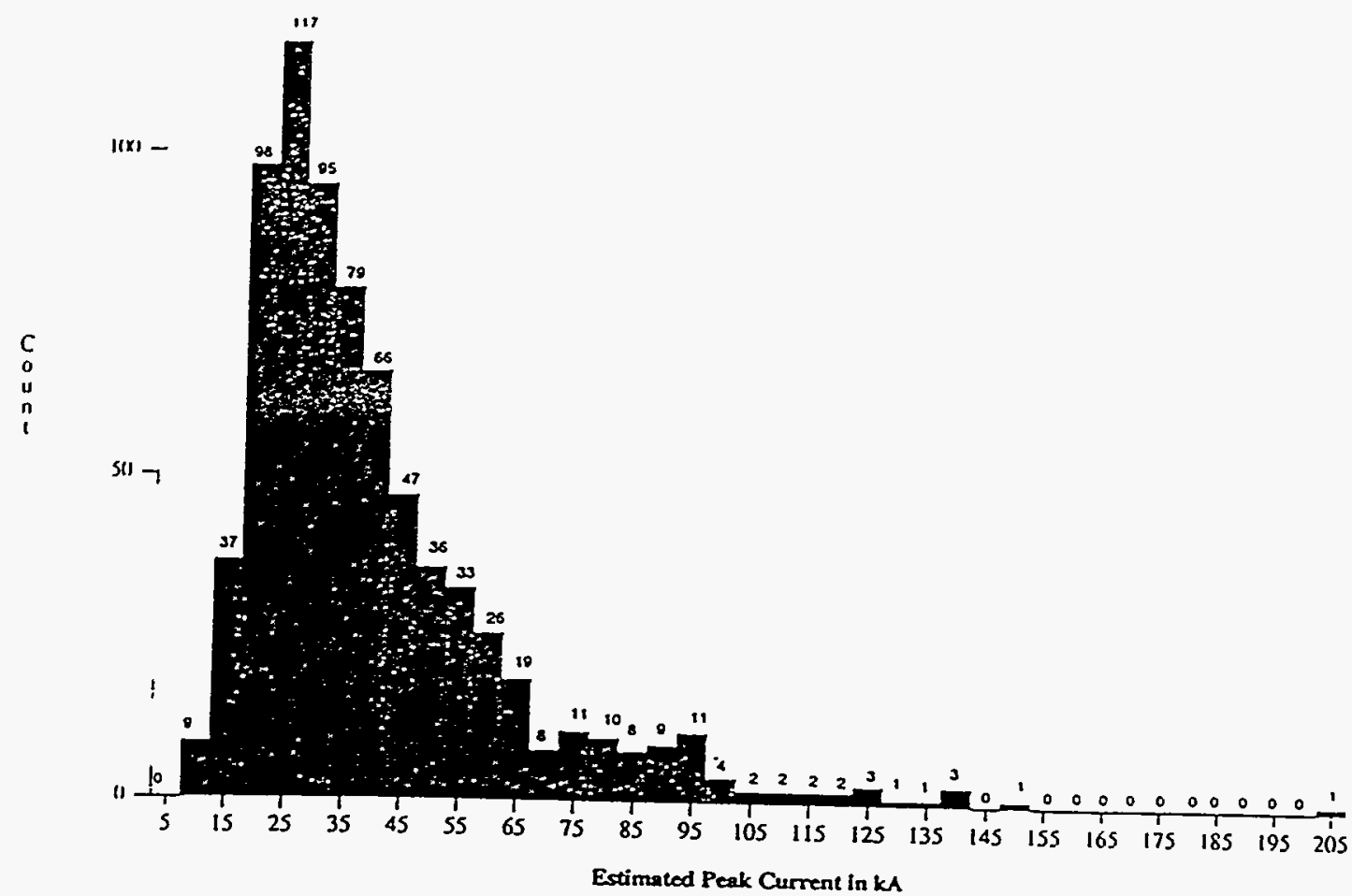

Fig. 3b. Histogram of NTS flash estimated peak current frequency (negative polarity).

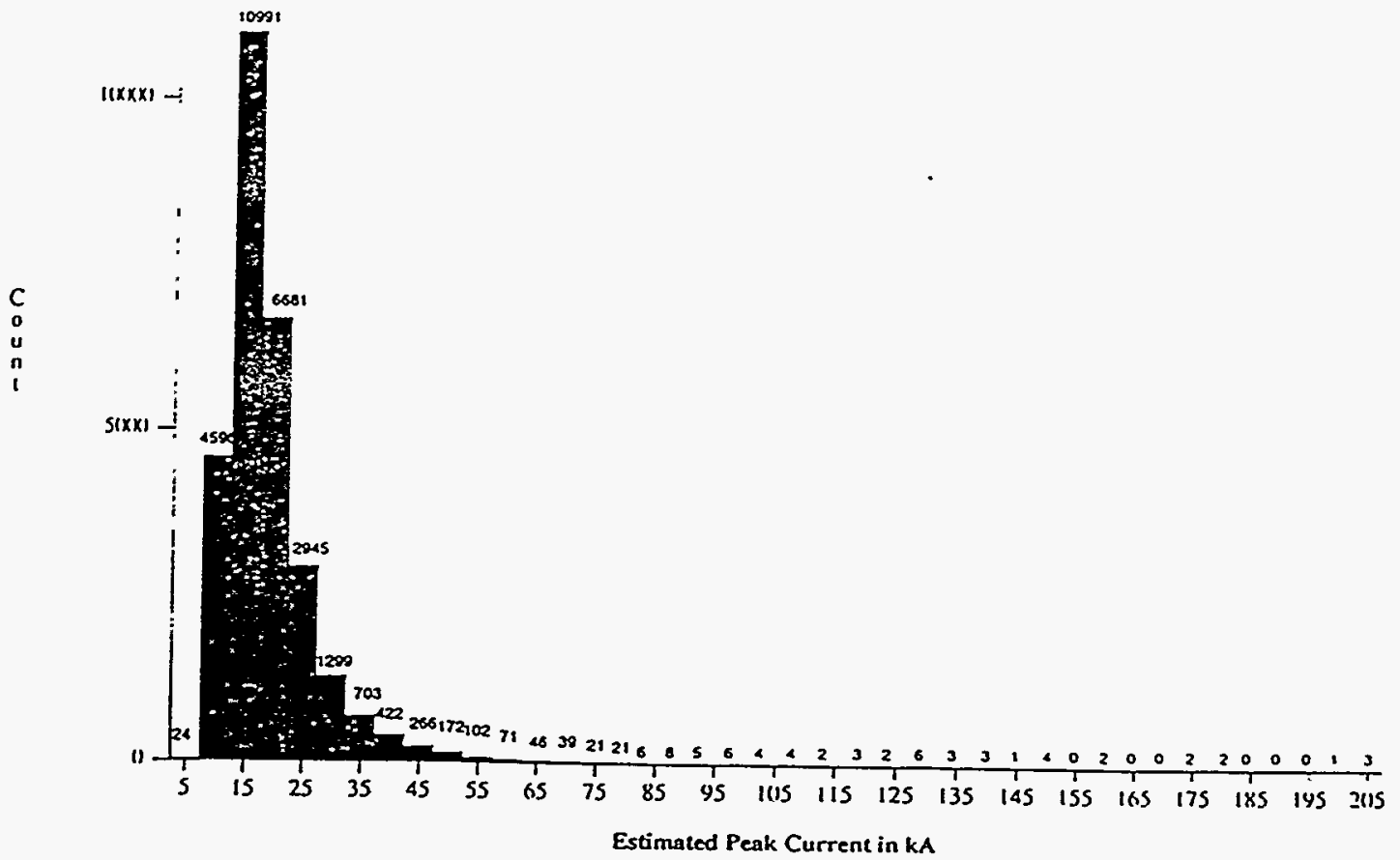


Fig. 4. NTS flash data presented as percent of flashes having an Ipk less than indicated value.

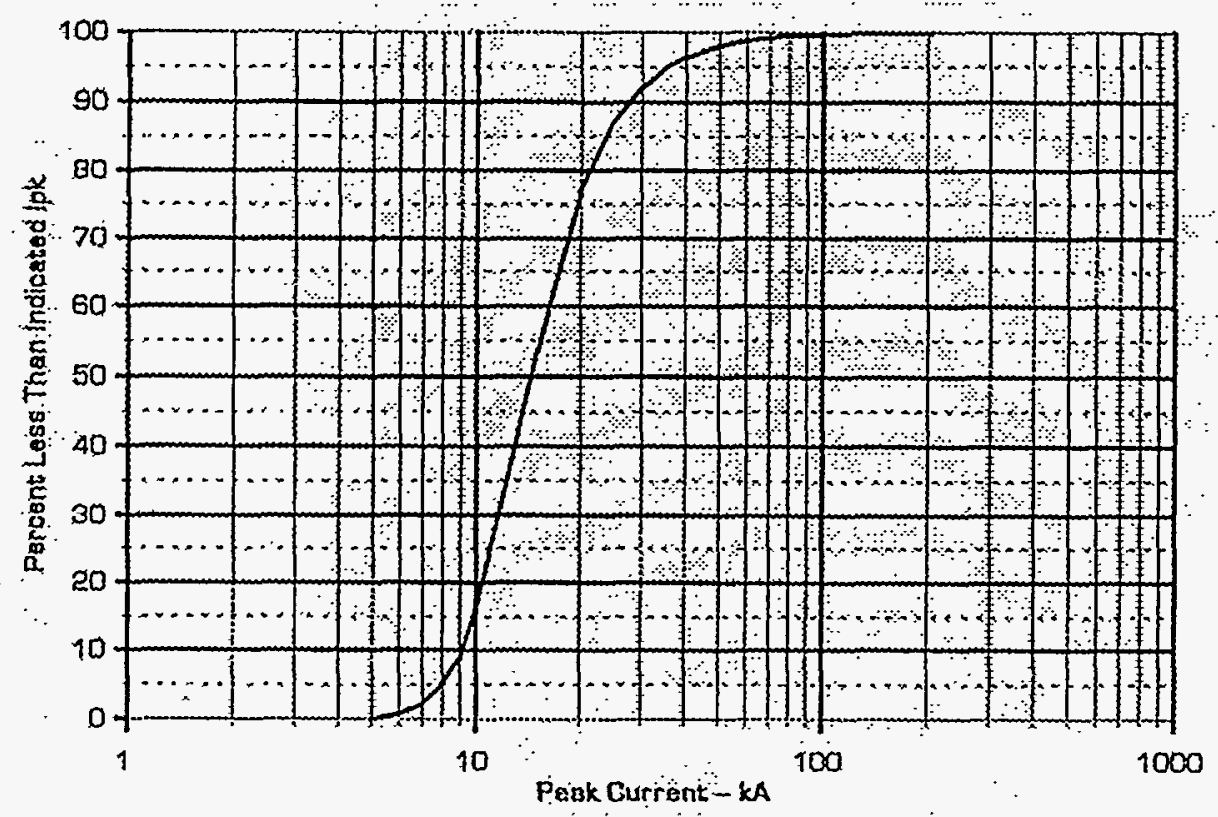

DAF Lightning Attractive Area

Since the $12,39-\mathrm{m}$-tall perimeter light poles appeared to be likely lightning strike points-at least for large-amplitude flashes-they were used in calculating the DAF's lightningattractive area. The design of the DAF facility is such that bases of the five poles in front are at the structure's floor-level elevation, the five rear poles rise from the roof-top elevation, and the poles at either end are at the median elevation. To facilitate calculations, an average pole height of $32 \mathrm{~m}$ above the structure's soil-covered roof-top was assumed.

As previously discussed, attractive area must take into account the peak amplitude of returnstroke current. Thus, an attractive area must be calculated for each current amplitude. The following method for dealing with the distribution of return-stroke currents is attributed to the late J. Stahmann of Boeing/Kennedy Space Center (Ref. 5). Stahmann assigned return-stroke peak currents from a large body of available data to deciles-i.e., 10\% of the total number of flashes being considered were placed into each of ten bins. The mean peak current per decile was then calculated.

\section{DAF Strike Probability}

Stahmann's mean peak-current per decile values were used to find the per-decile attractive area. The effect of the tall light poles on attractive area $\left(A_{a}\right)$ can be seen in Table 2, i.e., the surface area encompassed by the poles is $45 \mathrm{~km}^{2}$ while the attractive area for a $6-\mathrm{kA}$ stroke is $77 \mathrm{~km}^{2}$, and $171 \mathrm{~km}^{2}$ for a $112-\mathrm{kA}$ stroke. The product of the attractive area times the groundflash density provided per-decile probability, the sum of which gave cumulative probability in flashes per year (see Table 2). The reciprocal of cumulative probability, the mean return period (average strike frequency), was determined to be 17 years per flash. Next, the GAI (positive and negative) NTS flash data was placed into deciles (2921 flashes per decile) and the cumulative probability calculated (see Table 3 ). This yielded a strike frequency of 20 years per flash. 
Table 2. Method 1-Cumulative Probability of Strike to DAF (Generic $I_{p k}$ Values)

\begin{tabular}{|c|c|c|c|c|c|c|c|}
\hline Decile \# & $\begin{array}{c}\mathrm{l}_{\mathrm{pk}} \\
(\mathrm{kA})\end{array}$ & $\begin{array}{l}D_{s} \\
(m)\end{array}$ & $\begin{array}{c}r \\
(\mathrm{~m})\end{array}$ & $\begin{array}{c}A_{a} \\
\left(m^{2}\right)\end{array}$ & $\begin{array}{c}P_{0} \\
(f i / y r)\end{array}$ & $\begin{array}{c}P_{c} \\
(f l / y r)\end{array}$ & $\begin{array}{c}\text { B } \\
(y r / f l)\end{array}$ \\
\hline 1 & 6 & 33 & 33 & 76764 & $3.8 E-03$ & & $4 \%$ \% \\
\hline 2 & 13 & 53 & 48 & 93489 & 4.7E-03 & & 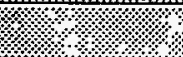 \\
\hline 3 & 18 & 65 & 56 & 101496 & $5.1 \mathrm{E}-03$ & & \\
\hline 4 & 23 & 76 & 62 & 108624 & $5.4 \mathrm{E}-03$ & & \\
\hline 5 & 28 & 88 & 68 & 115399 & $5.8 \mathrm{E}-03$ & & \\
\hline 6 & 35 & 101 & 74 & 122391 & $6.1 E-03$ & & \\
\hline 7 & 45 & 118 & 81 & 130658 & $6.5 \mathrm{E}-03$ & & \\
\hline 8 & 57 & 138 & 89 & 140196 & 7.0E-03 & & 4. \\
\hline 9 & 77 & 168 & 99 & 153061 & 7.6E-03 & & $\%$ \\
\hline 10 & 112 & 215 & 113 & 171380 & 8.6E-03 & 6E-02 & 17 \\
\hline
\end{tabular}

Table 3. Method 1-Cumulative Probability of Strike to DAF (NTS estimated $I_{p k}$ values)

\begin{tabular}{|c|c|c|c|c|c|c|c|}
\hline Decile \# & $\begin{array}{c}\mathrm{I}_{\mathrm{pk}} \\
(\mathrm{KA})\end{array}$ & $\begin{array}{l}D_{s} \\
(m)\end{array}$ & $\begin{array}{c}r \\
(m)\end{array}$ & $\begin{array}{c}A_{2} \\
\left(m^{2}\right)\end{array}$ & $\begin{array}{c}P_{0} \\
(f \mid / y r)\end{array}$ & $\begin{array}{c}P_{c} \\
(f \mid / y r)\end{array}$ & $\begin{array}{c}\mathrm{R} \\
(\mathrm{yr} / \mathrm{fl})\end{array}$ \\
\hline 1 & 7 & 34 & 34 & 77782 & 3.9E-03 & & . \\
\hline 2 & 13 & 52 & 48 & 93103 & 4. 7E-03 & & \\
\hline 3 & 14 & 55 & 50 & 94986 & 4.7E-03 & & \\
\hline 4 & 15 & 58 & 52 & 97289 & 4.9E-03 & & \\
\hline 5 & 16 & 62 & 54 & 99613 & 5.0E-03 & & \\
\hline 6 & 17 & 64 & 55 & 101188 & 5.1E-03 & & \% \\
\hline 7 & 20 & 70 & 59 & 105006 & 5.3E-03 & & ?. \\
\hline 8 & 23 & 77 & 63 & 109261 & $5.5 \mathrm{E}-03$ & & 筮 \\
\hline 9 & 28 & 88 & 68 & 115288 & $5.8 E-03$ & 8 & $\%$ \\
\hline 10 & 33 & 97 & 72 & 120234 & $6.0 \mathrm{E}-03$ & $5 E-02$ & 20 \\
\hline
\end{tabular}

Area enclosed by light poles: I $=312 \mathrm{~m}, \mathrm{w}=144 \mathrm{~m}\left(\mathrm{I} \times \mathrm{w}=44,928 \mathrm{~m}^{2}\right)$

$h=$ average height of poles above ground (roof-top) level $=32 \mathrm{~m}$

$I_{\text {pk }}=$ peak return-stroke current

$D_{s}=$ lightning striking distance $=10 \times l_{p k}^{0.65}$

$r=$ radius of light pole's attractive area $=\left(2 \times D_{s} \times h-h^{2}\right)^{0.5}$

$A_{a}=$ attractive area/decile $=(1+2 r) \times(w+2 r)-10[(4-\pi) / 4] r^{2}$

$\mathrm{F}_{\mathrm{g}}=$ ground flash density $=0.5 \mathrm{fl} / \mathrm{km}^{2} / \mathrm{yr}$ \{using $\mathrm{C}-\mathrm{G}$ detection network data for NTS \}

$P_{o}=$ strike probability/decile $=A_{a} \times\left(0.1 \times F_{g}\right) \times 10^{-6}$

$P_{c}=$ cumulative probability $=\Sigma P_{0}$

$R=$ mean return period (i.e., average strike frequency) $=1 / P_{c}$ 


\section{METHOD 2-FLASH PROGRAM}

FLASH is a PC program developed by F.J. Fisher, Lightning Technologies, Inc., and based upon the electrogeometric model of lightning. This model assumes that, for each peak amplitude value, there is a point where striking distance to ground and to an elevated object is equal, making the probabilities of a strike to ground and the object equal. The locus of these points is a spherical surface centered on and located above the object. This simple model does not take into account the effect of upward-going positive streamers on striking distance, but the effect isn't expected to be significant.

The FLASH program generates lightning flashes whose current amplitudes and points of origin are determined using a Monte-Carlo-type statistical approach. For the DAF, $x, y$, and $z$ (height above ground level) coordinates of the light poles were used. For the structure, the $z$ coordinate was zero since the rooftop level was defined as ground level. Three 8 - $m$-tall $H E P A$-filter vent stacks and two 1 -m-tall vent pipes (placed approximately at their actual roof-top locations) were also included (see Fig. 5). A 1-km $\times 1-\mathrm{km}$ square, centered on the structure, was selected as the area within which all the strikes were to fall. It is assumed that this program uses the traditional distribution of peak return-stroke currents. Results could be somewhat different if the NTS distribution is used, since the actual flash data indicates a much lower number of high-current flashes and a lower mean value.

Fig. 5. Plan view of DAF used with FLASH computer program.

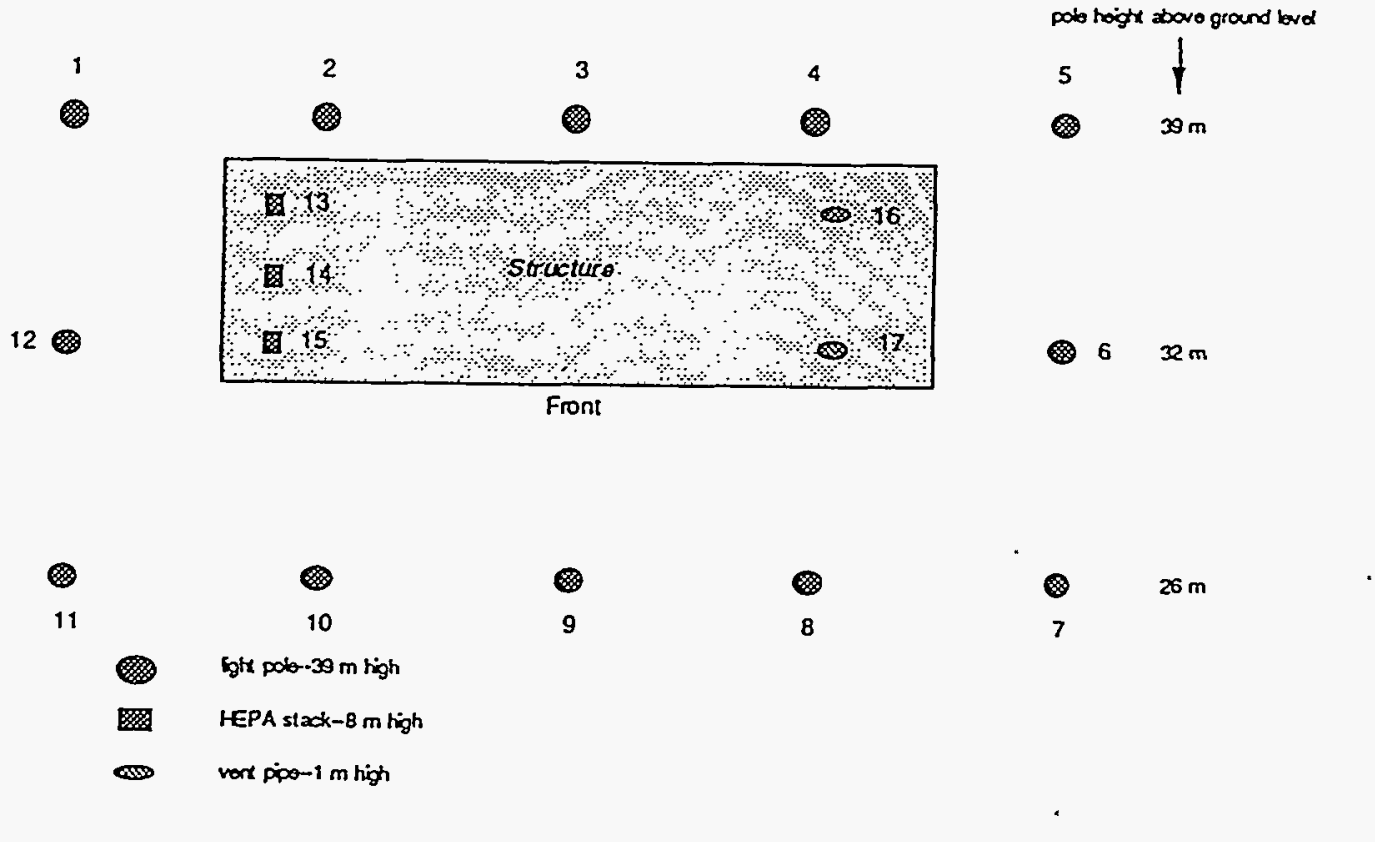


The cumulative results from three separate FLASH runs are as follows:

Total number of flashes per $\mathrm{km}^{2}\left(\mathrm{~F}_{1}\right)$

Total number of strikes to facility * $(n)$

Number of strikes attaching to tall poles

Amplitude range of strikes to structure

* includes light poles and structure
$=5,225$

$=714$

$=702$

$=5-29 \mathrm{kA}($ avg. $=16 \mathrm{kA})$

Determination of Probability:

$$
P_{s}=n / Y_{t}=n /\left(F_{t} / F_{g}\right)
$$

where $P_{s}=$ strike probability (strikes $/ y r$ )

$Y_{t}=$ number of years to accumulate $F_{t}$

$\mathrm{F}_{\mathrm{g}}=$ ground-flash density

$R=$ mean return period $=1 / P_{s}(y r /$ strike $)$

FLASH results appear in Table 4, and results from both methods are summarized in Table 5.

Table 4. Method 2-FLASH Program

\begin{tabular}{|c|c|c|c|c|}
\hline \multicolumn{2}{|c|}{ Point \# } & \multirow{2}{*}{$\begin{array}{c}\text { Strikes } \\
84\end{array}$} & \multirow{2}{*}{$\begin{array}{c}I_{p k} \text { (Average) } \\
(k A)\end{array}$} & \multirow{2}{*}{$\begin{array}{c}I_{p k} \text { (Range) } \\
(\mathrm{kA})\end{array}$} \\
\hline poles & 1 & & & \\
\hline & 2 & 76 & 49 & $16-200$ \\
\hline & 3 & 66 & 50 & $8-171$ \\
\hline & 4 & 59 & 46 & $4-134$ \\
\hline & 5 & 69 & 58 & $14-200$ \\
\hline & 6 & 48 & 52 & $8-200$ \\
\hline & 7 & 53 & 58 & $13-200$ \\
\hline & 8 & 46 & 37 & $7-135$ \\
\hline & 9 & 49 & 46 & $15-200$ \\
\hline & 10 & 50 & 54 & $13-200$ \\
\hline & 11 & 49 & 51 & $6-147$ \\
\hline & 12 & 61 & 49 & $8-200$ \\
\hline HEPA Vents & 13 & 1 & 5 & 5 \\
\hline & 14 & 0 & 1. & 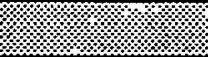 \\
\hline & 15 & 4 & 14 & $10-18$ \\
\hline vent pipes & 16 & 0 & & \\
\hline & 17 & 0 & & ( \\
\hline Roof top & & 7 & 20 & $10-29$ \\
\hline
\end{tabular}

Years to accumulate 5,225 flashes $\left(@ \mathrm{~F}_{\mathrm{g}}=0.50\right): 10,450 \mathrm{yr}$

Return period for strike to structure $\quad=10,450 \mathrm{yr} / 12$ strikes $=870 \mathrm{yr} /$ strike

Return period for strike to overall DAF $=10,450 \mathrm{yr} / 714$ strikes $=15 \mathrm{yr} / \mathrm{strike}$ 
Table 5. Summary of Results from Both Probability Calculation Methods

\begin{tabular}{|l|c|}
\hline \multicolumn{1}{|c|}{ Method } & $\begin{array}{c}\text { Mean Return Period, } F_{\mathrm{g}}=0.5 \\
(\mathrm{yr} / \mathrm{strike})\end{array}$ \\
\hline 1a. $\quad \begin{array}{l}\text { Cumulative Probability using } \\
\text { generic } \mathrm{I}_{\mathrm{pk}} \text { distribution }\end{array}$ & 17 \\
\hline 1b. $\quad \begin{array}{l}\text { Cumulative Probability using } \\
\mathrm{I}_{\mathrm{pk}} \text { distribution for NTS }\end{array}$ & 20 \\
\hline 2. $\quad$ FLASH Program & 15 \\
\hline
\end{tabular}

\section{CONCLUSION}

Reasonable strike probability estimates have been made using site-specific, ground-flash density values that are based upon actual NTS lightning data. It has been estimated that, for a ground-flash density of 0.5 flashes $/ \mathrm{km}^{2} / \mathrm{yr}$, some point of the DAF (structure and its perimeter light poles) will be struck by lightning - of some amplitude-approximately once every 20 years. It is interesting that the two significantly different methods yielded similar return periods, with the only factors in common being Love's striking-distance equation and ground-flash density.

The FLASH results predicted that, of the 5,225 computer-simulated strikes (equivalent to 10,450 years for a ground-flash density of 0.5 flashes $/ \mathrm{km}^{2} / \mathrm{yr}$ ), 86.3\% will strike the ground, not the DAF structure or light poles. The tall light poles will preferentially receive $13.4 \%$ of the strikes. Strikes reaching the structure $(0.2 \%)$ were of small to medium amplitude $(5-29 \mathrm{kA})$. (Note that actual flash data indicates that $90 \%$ of NTS lightning is equal to or less than $28 \mathrm{kA}$.)

\section{REFERENCES}

1. Golde, R.H., "Protection of Structures Against Lightning," Proceedings of the Institute of Electrical Engineers, Vol. 115, No. 10, pp. 1523-1529, 1968.

2. Golde, R.H., "The Lightning Conductor," in Golde, Lightning, Vol. 2, p. 560, Academic Press, London, 1977 (the striking distance equation attributed to E.R. Love).

3. Prentice, S.A., "Frequency of Lightning Discharges," in Golde, Lightning, Vol. 1, pp. 481 \& 487, Academic Press, London, 1977 (empirical ground-flash density relationships attributed to Cianos \& Pierce).

4. MacGorman, D.R., et al, Lightning Strike Density for the Contiguous United States From Thunderstorm Duration Records, Report No. NUREG/CR-3759, National Severe Storms Laboratory, Norman, OK, 1984.

5. Stahmann, J.R., "Launch Pad Lightning Protection Enhancement by Induced Streamers," Boeing Aerospace Operations, Kennedy Space Center, FL. 